\title{
The role of microbial quorum sensing on the characteristics and functionality of bioflocs in aquaculture systems
}

\begin{abstract}
The objective of this study was to elucidate the role of microbial cell-to-cell communication through quorum sensing (QS) mechanisms on bioflocs characteristics and functionality in aquaculture systems. This study comprised of four experimental stages, i.e. (1) inhibition of microbial aggregation and its effect on biofloc characteristics, (2) the effect of QS signal molecules addition on bioflocs characteristics and functions, (3) the effect of a QS signal molecule addition on bioflocs consumption by African catfish juvenile, and (4) quantification of QS molecule in a biofloc-based African catfish culture. For experiment one to three, bioflocs suspension was obtained from a biofloc sequencing batch reactor with a hydraulic retention time of $24 \mathrm{~h}$ using $\mathrm{N}-\mathrm{NH} 4 \mathrm{Cl}$ as the nitrogen source. Vanillin was used as a quorum sensing inhibitor in the first experiment to demonstrate the effect of a QS inhibitor on the formation of microbial aggregates in bioflocs and biofloc characteristics. The addition of vanillin at $0.30 \mathrm{mg} / \mathrm{L}$ significantly reduced microbioal aggregation, particle size and protein content of bioflocs. On the other hand, adding QS signal molecules significantly enhanced the protein content and the physical characteristics of bioflocs, as indicated by the increase in total suspended solids, floc volume, floc volume index and bioflocs particle size. Interestingly the addition of QS signal molecules notably increased the total ammoniacal nitrogen removal capacity of biofloc resuspension and the consumption of bioflocs by African catfish juveniles to almost double. The assessment of QS signal concentration in bioflocs pellet collected from biofloc-based African catfish production units at different culture age by using Chromobacterium violaceum 026 demonstrated that the concentrations of QS signals molecules increased with the increase of the culture age. In conclusion, the results of the present study clearly demonstrated that microbial quorum sensing plays some important roles in bioflocs characteristics and functionality in aquaculture systems.
\end{abstract}

Keyword : Bioflocs; Quorum sensing; Microbial aggregation; African catfish 